\title{
The Importance of Premotor Cortex for Supporting Speech Production after Left Capsular-Putaminal Damage
}

\author{
Mohamed L. Seghier, Juliana Bagdasaryan, Dorit E. Jung, and Cathy J. Price \\ Wellcome Trust Centre for Neuroimaging, Institute of Neurology, University College London, London, United Kingdom
}

The left putamen is known to be important for speech production, but some patients with left putamen damage can produce speech remarkably well. We investigated the neural mechanisms that support this recovery by using a combination of techniques to identify the neural regions and pathways that compensate for loss of the left putamen during speech production. First, we used fMRI to identify the brain regions that were activated during reading aloud and picture naming in a patient with left putamen damage. This revealed that the patient had abnormally high activity in the left premotor cortex. Second, we used dynamic causal modeling of the patient's fMRI data to understand how this premotor activity influenced other speech production regions and whether the same neural pathway was used by our 24 neurologically normal control subjects. Third, we validated the compensatory relationship between putamen and premotor cortex by showing, in the control subjects, that lower connectivity through the putamen increased connectivity through premotor cortex. Finally, in a lesion-deficit analysis, we demonstrate the explanatory power of our fMRI results in new patients who had damage to the left putamen, left premotor cortex, or both. Those with damage to both had worse reading and naming scores. The results of our four-pronged approach therefore have clinical implications for predicting which patients are more or less likely to recover their speech after left putaminal damage.

Key words: Premotor cortex; putamen; reading words; recovery pathways; subcortical stroke

\section{Introduction}

The putamen (PUT) is part of the basal ganglia system, which is known to play important roles in speech production (Rosen et al., 2000; Gil Robles et al., 2005; Tettamanti et al., 2005; Booth et al., 2007; Marchand et al., 2008; Seghier and Price, 2010; Oberhuber et al., 2013) and other motor control functions (Alexander and Crutcher, 1990; Kaji, 2001; Houk et al., 2007). A previous review of language in patients with subcortical lesions (Nadeau and Crosson, 1997) indicated that most patients with putamen damage have deficits at the level of motor execution of speech (e.g., dysarthria).

Three previous fMRI studies have investigated how some patients maintain or regain their language skills when the left putamen is no longer available. The first study showed strong activation in bilateral inferior frontal and superior temporal gyri during a sentence completion task in a patient with a left subcor-

\footnotetext{
Received May 14, 2014; revised Sept. 9, 2014; accepted Sept. 13, 2014.

Author contributions: C.J.P. designed research; M.L.S., J.B., D.E.J., and C.J.P. performed research; M.L.S., J.B., and C.J.P. analyzed data; M.L.S. and C.J.P. wrote the paper.

This work was funded by the Wellcome Trust and the James S. MacDonnell Foundation (conducted as part of the Brain Network Recovery Group initiative). We thank our three radiographers (Amanda Brennan, Janice Glensman, and David Bradbury), Clare Shakeshaft, Caroline Ellis, and Laura Stewart for their help with fMRI data collection; Sue Ramsden and Susan Prejawa for data management; and the PLORAS recruitment team (http://www.ucl.ac. uk/ploras/).

The authors declare no competing financial interests.

This article is freely available online through the J Neurosci Author Open Choice option.

Correspondence should be addressed to Dr. Mohamed L. Seghier, Wellcome Trust Center for Neuroimaging, Institute of Neurology, 12 Queen Square, London WC1N 3BG, UK. E-mail: m.seghier@ucl.ac.uk.

DOI:10.1523/JNEUROSCI.1954-14.2014

Copyright (c) 2014 Seghier et al.

This is an Open Access article distributed under the terms of the Creative Commons Attribution License (http://creativecommons.org/licenses/by/3.0), which permits unrestricted use, distribution and reproduction in any medium provided that the original work is properly attributed.
}

tical lesion that damaged the entire putamen (Kim et al., 2002). The second study showed that a patient with a "pure" left putaminal lesion named pictures with abnormally high activation in the left central sulcus and ventral angular gyrus (Fridriksson et al., 2005). The third study investigated therapy-induced changes to connectivity parameters during picture naming in a bilingual aphasic patient with damage to the left lentiform nucleus (Abutalebi et al., 2009). Plausibly, areas showing abnormally high activation in these patients may be parts of neural pathways that can support accurate speech production without the left putamen, but this was not formally tested. To explain how some patients might recover their speech production abilities better than others, we combined imaging and lesion-mapping techniques in a four-part study to investigate how speech production can be supported after left putamen damage.

In Part 1, we used fMRI in a 51-year-old patient with extensive left capsular-putaminal damage to identify brain areas with abnormally high activation during successful reading aloud and picture-naming responses. The identified areas became candidates for understanding the compensatory mechanisms that support speech after putaminal damage. In Part 2, we used dynamic causal modeling (DCM; Friston et al., 2003) of the patient fMRI data to test whether, and how, activation in the potentially compensating areas influenced the dynamics of activation in brain regions that control speech output. In Part 3, we validated the findings by testing whether the compensatory pathways used by the patient were also used in neurologically normal control subjects and, if so, how this depended on engagement of the putamen pathway. Any evidence for a tradeoff between pathways (i.e., strength of connectivity in one being inversely correlated with the strength of connectivity in another) would indicate that one 
pathway could compensate for another (Seghier et al., 2008, 2012). Finally, in Part 4, we tested the explanatory power of the findings in new patients who had damage to the putamen, the compensatory areas, or both. Our expectation was that speech would be worse when both pathways were damaged, even after controlling for lesion size.

\section{Materials and Methods}

The study was approved by the London Queen Square Research Ethics Committee. All participants gave informed consent.

\section{Part 1: identifying areas that might compensate for loss of the} left putamen

Subjects. A right-handed, female patient [PS0082 from the PLORAS (Predict Language Outcome and Recovery After Stroke) database; Price et al., 2010] and 24 neurologically normal right-handed control subjects were included in the fMRI study. All subjects spoke English as a native language. The patient experienced a stroke at the age of 51 years. Her lesion was located in the left lentiform nucleus at mean center MNI coordinates of $x=-26, y=-2, z=-2$, and with a total size of $35 \mathrm{~cm}^{3}$ (Fig. 1). As illustrated in Figure 1, the stroke completely damaged her left putamen, most of the globus pallidus, the claustrum, and a dorsal part of the left caudate nucleus. The lesion also damaged the internal capsule, particularly its anterior limb, and some parts of the external capsule, and extended dorsally into the neighboring white matter, which includes the superior occipitofrontal fasciculus and the corona radiata (Bürgel et al., 2006, see their Figs. 7 and 10 for an illustration of these tracts). In line with previous studies, we refer to this lesion as capsular-putaminal or striatocapsular damage (for discussion, see Naeser et al., 1982; Nadeau and Crosson, 1997).

Despite this damage, the patient was still able to produce correct responses during reading and naming when we first tested her 15 months after her stroke using all subtests of the Comprehensive Aphasia Test (CAT; Swinburn et al., 2004), which assesses cognitive, receptive, and expressive speech abilities. Specifically, the CAT defines behavioral $t$ scores for individual patients in a set of 34 different tasks. As detailed in Swinburn et al. (2004), each score defines how a given patient performed relative to a distribution of 60 patients with poststroke aphasia. The threshold of impairment in each task is derived from a second population of 27 people with normal language and cognition. The threshold of impairment thus varies with task. Performance below the threshold implies that the patient would be in the bottom $5 \%$ of that in the normal population. Note that aphasic patients can score within the normal range on many of the subtests of the CAT; this occurs most frequently when patients have relatively mild aphasia or when the subtests are relatively easy (for detailed discussion, see Howard et al., 2010). Overall, within each task, lower $t$ scores indicate poorer performance. The patient's scores for each test can be seen in Table 1 . The only scores still in the aphasic range were observed for auditory repetition of words and nonwords. Repetition errors were mainly phonemic paraphasias affecting just one phoneme (i.e., errors were in the place and manner of articulation, but rarely in voicing). There was no clear effect of the number of syllables or consonant combinations.

The control group consisted of 24 healthy right-handed subjects ( 11 females, 13 males; mean age, $26 \pm 18$ years), who also participated in our previous study (Seghier and Price, 2010). Subjects were native English speakers, had normal or corrected-to-normal vision, and had no history of neurological or psychiatric disorders. Those 24 subjects were included in the present study because they showed robust activation at our regions of interest (ROIs) used in the DCM analysis (as detailed below).

Details of the fMRI experiment. During two separate scanning sessions, subjects were asked to (1) read aloud 96 three to six letter object names with consistent spelling-to-sound relationships (e.g., hat, tent, horse, carrot); (2) name presented pictures of familiar objects; and (3) say " 1,2 , 3 " to meaningless symbols or pictures of nonobjects (unfamiliar stimuli). In each session, there were four different blocks of each stimulus type. Within a block (18 s), 12 stimuli were presented at a rate of three (as a "triad"), with 1 stimulus above and 2 below (comprising 4 triads of
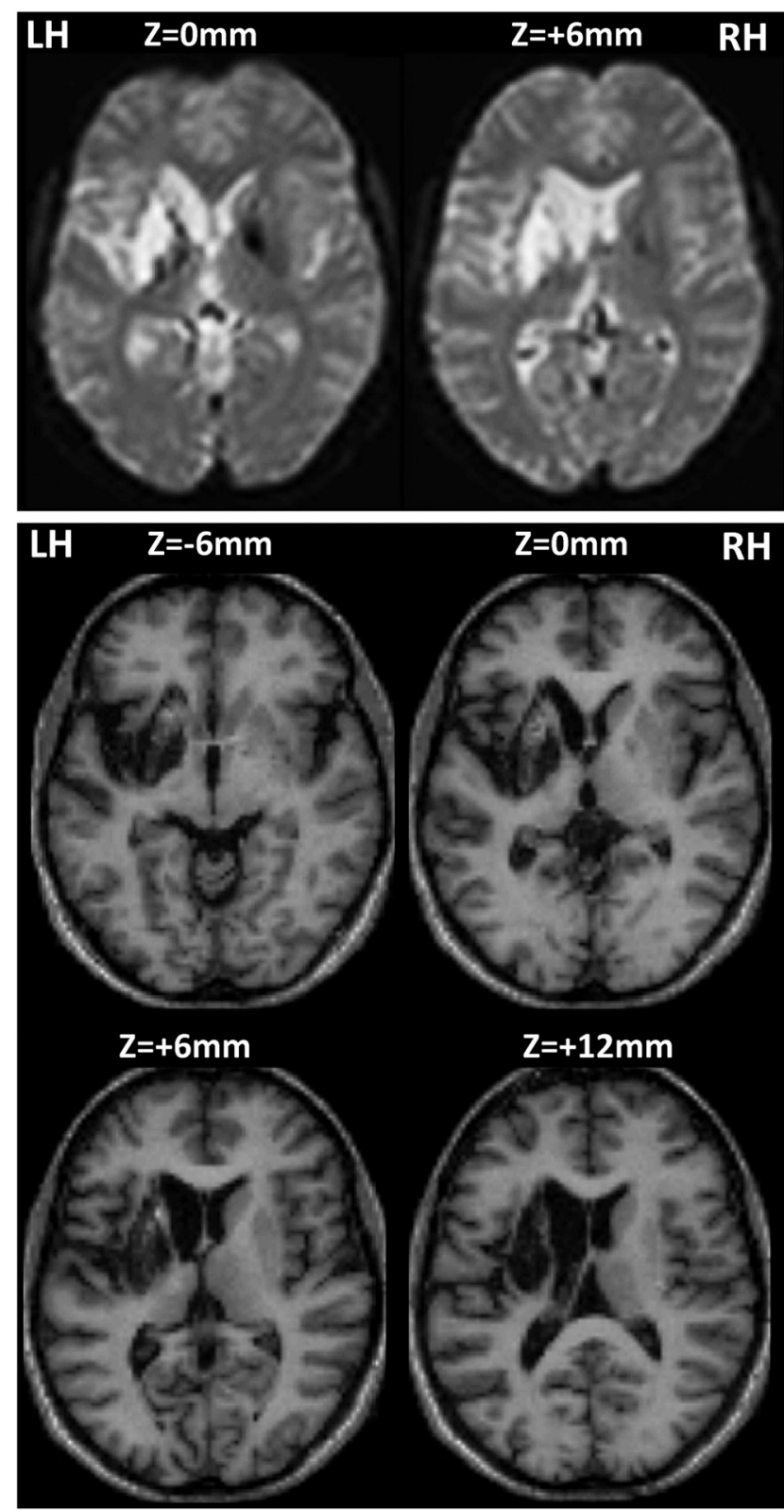

Figure 1. An illustration of the extent of the patient's lesion in the left capsular-putaminal zone, shown in axial views of the EPI (top) and the T1-weighted anatomical scan (bottom). The coordinates in the MNI space are provided at the top of each axial slice. LH, Left hemisphere; RH, right hemisphere.

stimuli). The interval between the onset of each triad was always $4.5 \mathrm{~s}$. This encouraged the patient and healthy subjects to respond as rapidly as possible (with a maximum of a mean $1.5 \mathrm{~s}$ per stimulus). The same triads were presented as words and pictures across participants (to equate articulation responses). Only trials where all three stimuli in a triad were read or named correctly were considered as correct trials. Each block was preceded by $3.6 \mathrm{~s}$ of instructions (e.g., READ, NAME), and the patient was able to read and understand the written instructions. The order of conditions was counterbalanced within the session with six blocks of fixation (14.4 s each), one every two stimulus blocks.

For the reading and object-naming conditions, all stimuli were derived from a set of 192 objects with three to six letter common names with regular spelling-to-sound relationships: 33 objects had three-letter names (cat, bus, hat), 65 had four-letter names (ship, bell, frog, hand), 58 had five-letter names (teeth, camel, snake), and 36 had six-letter names (spider, dagger, button). The majority $(n=140)$ of these object names 
Table 1. Behavioral scores during all the subtests of the CAT

\begin{tabular}{ll}
\hline CAT subtest & tscore \\
\hline Speech production tasks & \\
Spoken picture description & 66 \\
Fluency & 57 \\
Object naming & 60 \\
Action naming & 63 \\
Reading words & 61 \\
Reading complex words & 57 \\
Reading functional words & 62 \\
Reading nonwords & 61 \\
Repetition of words & $51^{*}$ \\
Repetition of complex words & 62 \\
Repetition of nonwords & $51^{*}$ \\
Repetition of sentences & 63 \\
Digit span & 59 \\
Comprehension & \\
Semantic memory & 60 \\
Recognition memory & 48 \\
Comprehension of spoken words & 51 \\
Comprehension of spoken sentences & 65 \\
Comprehension of spoken paragraphs & 60 \\
Comprehension of written words & 55 \\
Comprehension of written sentences & 64 \\
Other cognitive and motor tasks & \\
Gesture object use & 60 \\
Arithmetic & 65 \\
Line bisection & 59 \\
Copying & 61 \\
Written picture name & 62 \\
Writing to dictation & 68 \\
Written picture description & 71 \\
*Varthatare atyicall lowinthe & \\
\hline
\end{tabular}

*Values that are atypically low in the patient compared to normal range (i.e. in aphasic range).

were monosyllabic (e.g., bell, bus, horse, dog), 47 were bisyllabic (carrot, flower, spider, window), and five were trisyllabic (camera, onion, piano, potato, tomato; Hu et al., 2010). There was no obvious semantic relationship among the three different objects in the triad (e.g., slide, axe, cup).

The accuracy of vocal responses during all conditions was recorded with an MRI-compatible microphone. To minimize artifacts from head motion and airflow caused by the mouth opening and closing, subjects were instructed to whisper their response with minimal mouth movement. Although a sound cancellation system allowed us to identify the accuracy of vocal response, it was not possible to extract the response times. Stimulus presentation was via a video projector, a front projection screen, and a system of mirrors fastened to a head coil. Additional details about the paradigm and stimuli can be found in our previous work (Josse et al., 2008; Seghier and Price, 2011).

MRI acquisition. Experiments were performed on a $1.5 \mathrm{~T}$ scanner (Siemens Medical Systems). Functional imaging consisted of a gradient-echo EPI sequence (TR, $3600 \mathrm{~ms}$; TE, $50 \mathrm{~ms}$; flip angle, 90 ; FOV, $192 \mathrm{~mm}$; matrix, $64 \times 64 ; 40$ axial slices, $2 \mathrm{~mm}$ thick with a $1 \mathrm{~mm}$ gap). Functional scanning was always preceded by $14.4 \mathrm{~s}$ of dummy scans to ensure tissue steady-state magnetization. An anatomical scan was also acquired and later used for spatial normalization as described below. This was a $3 \mathrm{D}$ T1-weighted, modified equilibrium Fourier transform sequence with the following parameters: TR, $12.24 \mathrm{~ms}$; TE, $3.56 \mathrm{~ms}$; TI, $530 \mathrm{~ms}$; FOV, $256 \times$ $224 \mathrm{~mm}$; acquisition matrix, $256 \times 224 ; 1 \mathrm{~mm}$ slice thickness for $1 \mathrm{~mm}^{3}$ isotropic voxels.

fMRI data analysis. Data-processing and statistical analyses were performed with the Statistical Parametric Mapping SPM5 software package (Wellcome Trust Centre for Neuroimaging, London, UK; http://www. fil.ion.ucl.ac.uk/spm/). All functional volumes were spatially realigned, unwarped, normalized to the MNI space using the unified normalization-segmentation procedure of SPM5, and smoothed with an isotropic $6 \mathrm{~mm}$ FWHM Gaussian kernel, with a resulting voxel size of $2 \times 2 \times 2$ $\mathrm{mm}^{3}$. Time series from each voxel were high-pass filtered $(1 / 128 \mathrm{~Hz}$ cutoff) to remove low-frequency noise and signal drift. The preprocessed functional volumes of each subject were then submitted to a fixed-effects analysis, using the general linear model at each voxel. Each stimulus onset was modeled as an event encoded in condition-specific "stick functions" with an interstimulus interval of $4.5 \mathrm{~s}$ and a duration of $4.32 \mathrm{~s}$ per trial. Trials were grouped by blocks of four events (near to the configuration of a block design). The resulting stimulus functions were convolved with a canonical hemodynamic response function to form regressors for the linear model.

For each subject (patient and control subjects), we computed the contrast images for naming, reading, and saying " $1,2,3$," each relative to fixation. These images were then entered into a second-level analysis (i.e., random-effects analysis) with patient and control subjects modeled separately so that we could identify areas where the patient activated more or less than normal during each of the tasks. The analysis was performed with SPM, which estimates $t$ values after computing a pooled variance, based on the assumption that the patient's brain response constitutes the mean value of a (hypothetical) population with a variance equal to that of the control group (for a similar procedure, see Mühlau et al., 2009). This pooled approach in SPM is equivalent to the Crawford-Howell modified $t$ test (Crawford and Howell, 1998). We expected that activation in the damaged left putamen would be less than normal (i.e., absent). Any areas that were more activated than normal were identified as candidates for "compensatory areas/pathways" that might be able to support speech production after left putaminal damage. Only effects that were positive (i.e., positive effect size relative to fixation) in the patient and control subjects were retained (i.e., relative differences in deactivations were omitted). The resulting candidates for compensatory areas/pathways after left putamen damage were subsequently validated by showing a negative correlation in activation/connectivity for the candidate regions and the left putamen.

\section{Part 2: identifying whether and how the compensatory areas contribute to speech production}

Having identified the neural regions that support reading and picture naming in the patient with left putamen damage, we investigated how the identified regions contributed to speech production. To achieve this, we used DCM (Friston et al., 2003) to assess task-related directional functional connectivity, which indicates how brain activity is propagated through the speech production system. The main advantage of DCM is the opportunity to estimate how the rate of change of activity in one region influences the rate of change in other regions (Friston et al., 2003). This in turn leads to information about the direction of the influence one brain region may have on another rather than implying a nondirectional correlation. The parameterization of the hemodynamic model in DCM is region specific, which makes DCM reasonably robust in the event of stroke-related disturbances of the neurovascular coupling. More details about DCM can be found elsewhere (Friston et al., 2003; Seghier et al., 2010).

We have already developed a multistage DCM procedure (Seghier et al., 2012) that expresses the difference between a patient and control subjects in terms of increased or reduced coupling between pairs of regions (for more details, see also Seghier et al., 2010). The expectation here is that recovery might be enabled by a boost in effective connectivity through one or more alternative pathways (Seghier et al., 2012). All DCM analyses were performed in SPM8.

ROI selection. A total of six ROIs were selected for subsequent DCM analyses. Five of these regions were the same as those used in our previous study of reading networks in the same neurologically normal control subjects used here (Seghier and Price, 2010). All five of these regions were significantly more activated during reading than fixation in the control subjects, and all but the putamen were significantly activated for reading relative to fixation in the patient (Table 2 , list of coordinates). The first region was in the ventral occipital cortex (vOCC) and served as the input area where sensory stimuli drive activation through the system. This is essential for the deterministic DCM algorithm used here, and enables the analysis to quantify how driving regions respond to external stimuli (see next section for more details). The second region was in the anterior part of the ventral occipito-temporal sulcus (aOT) and is associated with word and object recognition. The third and fourth areas were the thala- 
Table 2. MNI coordinates of the ROIs for the patient and average coordinates for controls

\begin{tabular}{lll}
\hline ROI & Patient & Control subjects \\
\hline vOCC & $-34-82-16$ & $-34-84-12$ \\
aOT & $-42-46-20$ & $-42-44-16$ \\
THA & $-8-184$ & $-10-186$ \\
PM & -38632 & -36826 \\
MC & $-50-1436$ & $-48-1236$ \\
PUT & $-26-2-2$ & -2206 \\
\hline
\end{tabular}

Values are given as $[x, y, z]$ MNI coordinates. THA, Thalamus. subjects (i.e., with an intact putamen). For a given model, DCM estimates the following three different sets of effective connectivity parameters, corresponding to different kinds of matrices: (1) input parameters (i.e., the C-matrix) that quantify how brain regions respond to external stimuli; (2) endogenous parameters (i.e., the A-matrix) reflecting the average or baseline connectivity that characterizes the coupling between regions in the absence of external inputs; and (3) modulatory parameters (i.e., the B-matrix) that measure changes in effective connectivity induced by experimental conditions. These different parameters are expressed in hertz within the DCM framework.

Our DCM models were defined as follows: (1) all visual triads with correct responses were grouped as a single driving input that entered the system at vOCC; (2) all regions were connected reciprocally and were modeled by bidirectional connections, except a direct connection between vOCC and MC (Seghier and Price, 2010); and (3) connections to and from the putamen were varied, yielding 31 possible models in total (Fig. 2, illustration), which allowed us to test how the model evidence changed as the number of connections with the putamen increased. MC was considered as the system output region, which received inputs from all regions except vOCC, because we did not expect a direct causal influence from visual areas on primary motor cortices. Our models thus tested how information propagated from vOCC to MC through one or more intermediate regions. All connections were modulated by the following two parameters: correct trials with meaningful stimuli "naming plus reading"; and their difference "naming minus reading." This allowed us to distinguish between modulatory effects for naming and reading relative to saying " $1,2,3$," as well as the differences between reading and naming.

Subsequently, Bayesian model selection was performed over the entire DCM space of 31 models, and we used Bayesian model averaging

Figure 2. A schematic illustration of the 6-region models used in the patient and healthy control subjects. Connections bidirectional connections involved the putamen).

mus and the putamen. The fifth region was located in the motor cortex (MC), where speech production activity culminates in outputting motor commands for articulation. The sixth region was an area in the left premotor cortex (PM) that was not included in our previous DCM study but was included here because it was found, in Part 1 of this study, to be more activated during reading and naming in the patient than in the healthy control subjects (for details, see the results of Part 1).

Data (i.e., the time series of BOLD activity) were extracted and adjusted to the F-contrast, from each of our six ROIs, at the exact coordinates listed in Table 2 in the patient or within $6 \mathrm{~mm}$ distance of the group coordinates $(p<0.05$, uncorrected) for each healthy control subject. This restriction is necessary so that DCM models are consistent and can be compared across subjects (Seghier et al., 2010). In the patient, the absence of activation in the damaged left putamen meant that we had to reduce the statistical threshold until a noisy signal could be extracted (for a similar rationale, see Seghier et al., 2012). It was not possible (1) to replace the intact putamen with a noisy region in control subjects because, statistically speaking, this is not valid, as the influence of the intact putamen on other regions is already recorded in the collected time series of other nodes; or (2) to completely omit the putamen in control subjects because Bayesian model comparison operates only in models with the same regions. As discussed in Seghier et al. (2010), our approach is a good approximation of a system with damaged putamen, and it allows the contribution of this region in both the patient and control subjects to be assessed (i.e., as a dysfunctional or an intact node, respectively). All six regions were significantly activated during speech production in the control subjects. Data from the two speech production sessions were then concatenated for each subject separately, before being incorporated in DCM analyses.

DCM analysis. Our DCM analyses were performed separately on the patients (i.e., with a dysfunctional putamen) and the healthy control
(Penny et al., 2010) to estimate the posterior values of the different connectivity parameters over the whole model space. The results (optimal model and individual connection strengths) were then compared in the patient and the control subjects. We expected the patient to have abnormally low connectivity through the damaged putamen but abnormally strong connectivity in any pathway that might be compensating for loss of the left putamen. We used a Crawford-Howell modified $t$ test (Crawford and Howell, 1998) to look for enhanced connectivity in the patient compared with our 24 healthy control subjects.

Part 3: validating the patient findings by testing whether and how the compensatory pathways are used in neurologically normal control subjects

On the basis of our prior work (Seghier et al., 2012), we predicted that, if one pathway can compensate for another, this might be expressed as intersubject variability in the control group. Specifically, within the control subjects, we investigated whether the strength of connectivity through the left putamen was inversely related to the strength of connectivity through the pathway that was compensating for loss of the putamen in the patient. Such a finding would also demonstrate dissociable neuronal pathways for the same task across healthy subjects.

\section{Part 4: testing the explanatory power of the findings in other}

Using independent data, this lesion deficit analysis tested whether other patients with damage to the left putamen were more likely to recover if the alternative pathway through the premotor cortex is intact than if it is damaged. Put another way, if the premotor cortex was required to support reading and naming after damage to the left putamen, we predicted patients with left putaminal damage 
Table 3. Endogenous connectivity

\begin{tabular}{|c|c|c|c|c|c|c|}
\hline & $\mathrm{VOCC}$ & $\mathrm{aOT}$ & THA & PM & $M C$ & PUT \\
\hline \multicolumn{7}{|l|}{ Patient } \\
\hline VOCC & & 0.11 & 0.13 & 0.15 & & 0.00 \\
\hline $\mathrm{aOT}$ & 0.26 & & 0.11 & 0.10 & 0.03 & 0.00 \\
\hline THA & 0.29 & 0.14 & & 0.19 & 0.10 & 0.00 \\
\hline PM & 0.26 & 0.14 & 0.18 & & 0.11 & -0.01 \\
\hline$M C$ & & 0.20 & 0.25 & 0.25 & & -0.01 \\
\hline PUT & 0.01 & -0.01 & -0.01 & -0.01 & -0.03 & \\
\hline \multicolumn{7}{|c|}{ Control subjects } \\
\hline vOCC & & 0.10 & 0.06 & 0.09 & & 0.04 \\
\hline $\mathrm{aOT}$ & 0.24 & & 0.08 & 0.10 & 0.11 & 0.05 \\
\hline THA & 0.20 & 0.08 & & 0.07 & 0.07 & 0.03 \\
\hline PM & 0.22 & 0.10 & 0.08 & & 0.09 & 0.03 \\
\hline MC & & 0.28 & 0.23 & 0.26 & & 0.14 \\
\hline PUT & 0.13 & 0.05 & 0.04 & 0.04 & 0.06 & \\
\hline
\end{tabular}

Values are given in hertz; those in bold are $p>0.90$. THA, thalamus.

Table 4. Individual reading and naming scores in 41 patients with damage to the left putamen and/or the left premotor cortex

\begin{tabular}{|c|c|c|c|c|c|c|c|c|}
\hline \multirow[b]{2}{*}{ Groups } & \multicolumn{2}{|l|}{ Group 1} & \multicolumn{2}{|l|}{ Group 2} & \multicolumn{2}{|c|}{ Group $3 \mathrm{~A}$} & \multicolumn{2}{|c|}{ Group 3B } \\
\hline & Reading & Naming & Reading & Naming & Reading & Naming & Reading & Naming \\
\hline 1 & 38 & 37 & 62 & 61 & 38 & 43 & 54 & 61 \\
\hline 2 & 45 & 46 & 50 & 61 & 39 & 57 & 62 & 62 \\
\hline 3 & 47 & 58 & 56 & 60 & 61 & 58 & 60 & 64 \\
\hline 4 & 53 & 47 & 40 & 44 & 61 & 61 & 60 & 74 \\
\hline 5 & 47 & 43 & 62 & 61 & 52 & 50 & 49 & 60 \\
\hline 6 & 48 & 52 & 57 & 64 & 46 & 54 & 64 & 64 \\
\hline 7 & & & 53 & 58 & 62 & 58 & 38 & 44 \\
\hline 8 & & & 69 & 74 & 53 & 55 & & \\
\hline 9 & & & 60 & 58 & 57 & 52 & & \\
\hline 10 & & & 69 & 66 & 54 & 53 & & \\
\hline 11 & & & 62 & 64 & 53 & 49 & & \\
\hline 12 & & & 61 & 62 & 60 & 74 & & \\
\hline 13 & & & 46 & 45 & 64 & 66 & & \\
\hline 14 & & & & & 69 & 74 & & \\
\hline 15 & & & & & 38 & 37 & & \\
\hline Mean & 46.3 & 47.2 & 57.5 & 59.9 & 53.8 & 56.1 & 55.3 & 61.3 \\
\hline SD & 4.9 & 7.3 & 8.5 & 8.0 & 9.8 & 10.1 & 9.2 & 8.9 \\
\hline$t$ values* & & & 2.97 & 3.31 & 1.76 & 1.95 & 2.14 & 3.9 \\
\hline$p$ values* & & & 0.004 & 0.002 & 0.05 & 0.03 & 0.03 & 0.005 \\
\hline
\end{tabular}

Values are individual scores, unless otherwise indicated. Group 1: size, $90-194 \mathrm{~cm}^{3}$; age, $36-74$ years; Group 2: size, 26-97 $\mathrm{cm}^{3}$; age, 41-71 years; Group 3A: size, $97-180 \mathrm{~cm}^{3}$; age, $44-77$ years; Group 3B: size, 31- $84 \mathrm{~cm}^{3}$; age, $49-77$ years.

*Group 1 versus group in that column.

that deficits would be worse in patients with damage to both the putamen and premotor cortex than in patients with damage to either the putamen or the premotor cortex.

Patients were selected from the PLORAS database (Price et al., 2010) that links structural scans from hundreds of patients with their standardized language scores and demographic details. All patients are tested on all subtests of the CAT (Swinburn et al., 2004). From this repository, we searched for right-handed patients with (1) left hemisphere stroke (time poststroke, >3 months); (2) English as their native language; and (3) damage to the left putamen, the left premotor cortex, or both. The search for lesions at our regions of interest was made possible thanks to the fact that all patients in the PLORAS database had their lesions delineated at high spatial definition in the MNI space. Our regions of interest were spheres ( $8 \mathrm{~mm}$ diameter) centered at the MNI coordinates of the putamen and premotor activations observed in the control subjects (Table 2). We searched for patients who had $>75 \%$ damage to either of these areas.

There were 42 right-handed native English speakers who met our criteria (for details, see Table 4). They were split into four groups according to their lesion location and size. Group 1 included seven patients with $>75 \%$ damage to both regions. Group 2 included 13 patients with $>75 \%$ damage to the putamen only. The patient included in the fMRI analysis
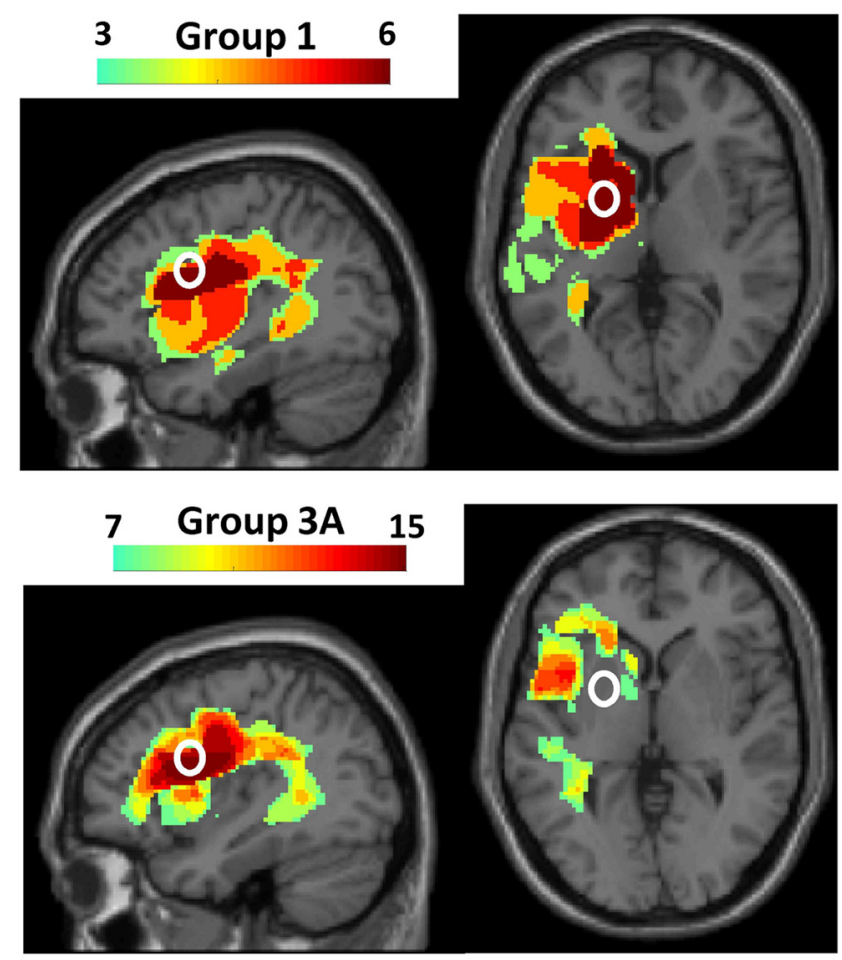

Figure 3. illustrates the lesion overlap maps of Group 1 (top) and Group 3A (bottom) that differ in whether the putamen was damaged (Group 1) or not (Group 3A). The color in the axial and sagittal views indicates the number of patients who had a lesion at each brain voxel. Voxels in dark red were damaged in all patients of each group. The white circle shows the location of our regions of interest in the left putamen (axial view) and the left premotor cortex (sagittal view). For illustration purposes, only voxels damaged in $>50 \%$ of patients in each group are shown.

(PS0082) also met the criteria for Group 2 but was not included in the lesion analysis. She was the first patient to be tested with a relatively discrete left putamen lesion, hence her inclusion in the fMRI study. By the time the other 13 patients were recruited, the scanner and fMRI protocol we were using had changed. Group 3 included 22 patients with $>75 \%$ damage to premotor cortex only. This group was split into two parts on the basis of lesion size. Group 3A $(n=15)$ had the same range of lesions as Group $1\left(90-194 \mathrm{~cm}^{3}\right)$. Group 3B $(n=7)$ had a smaller range of lesions $\left(31-84 \mathrm{~cm}^{3}\right)$. The range of lesion sizes in Group 2 were also smaller than those in Group $1\left(26-97 \mathrm{~cm}^{3}\right)$. The standardized reading and naming scores of Group 1, as derived from the CAT, were compared with those of Groups 2 and 3 using two-sample one-tailed $t$ tests. One outlier, from Group 1, was excluded because the patient's score was abnormally far ( $>2$ SDs) above the mean scores of that group.

One practical issue here is that a lesion that damaged a combination of regions (putamen and left premotor cortex) is likely to be larger than lesions that damaged individual sites. Here we account for this factor by matching lesions for size in patients in Group 1 and Group 3A (Fig. 3, illustration of the lesion overlap across patients of both groups). Crucially, a combination of lesions would not necessarily result in worse performance by virtue of its size alone; a combination of lesions should only lead to worse performance if, and only if, critical sites (e.g., alternative pathways) are included. For instance, across 94 patients with subcortical damage, Miyai et al. (2000) examined motor outcome in patients with damage to both putamen and thalamus (and internal capsule) versus patients with damage to either putamen or thalamus. They found, perhaps surprisingly, that patients with damage to both structures had better performance and recovery than patients with damage to either structure alone, with this finding being interpreted by the fact that their combination of lesions did not include critical motor regions (for discussion, see Miyai et al., 2000). Indeed, a few studies have highlighted the importance of the structural integrity of critical regions in supporting 

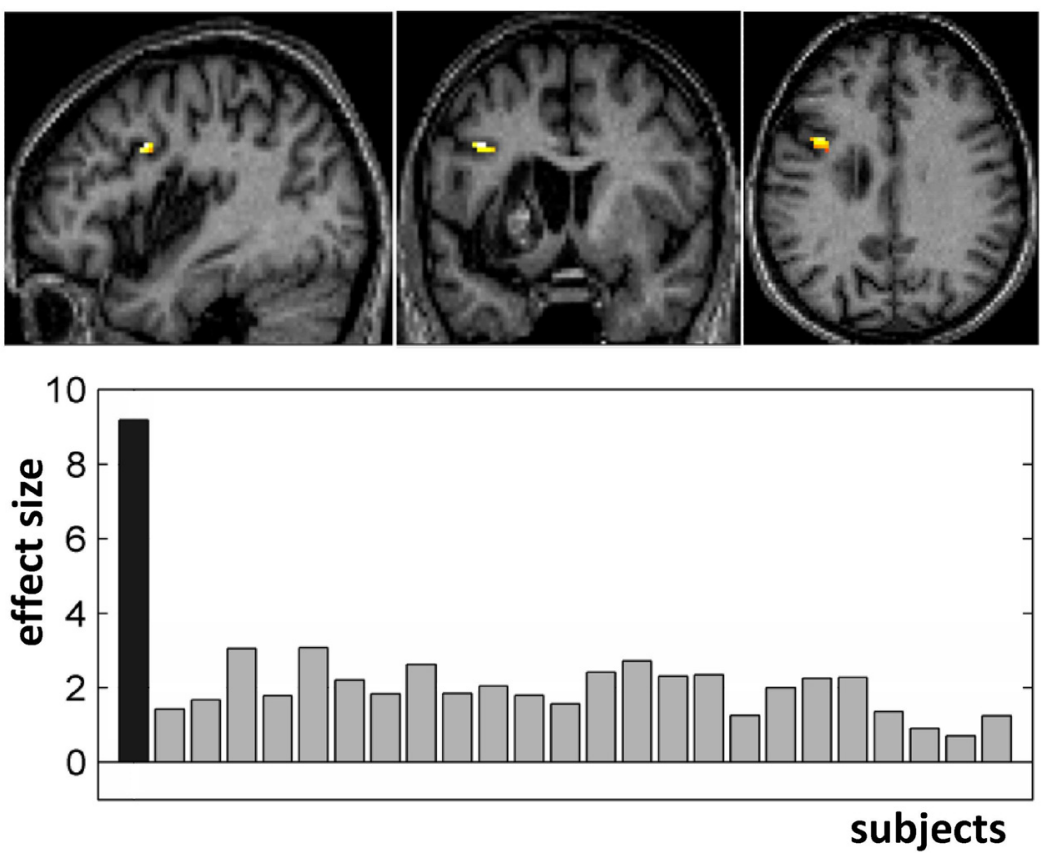

Figure 4. Top, The area of left premotor cortex (in yellow) that was activated by reading relative to saying" $1,2,3^{\prime \prime}$ to meaningless symbols in the patient more than in the 24 healthy control subjects (MNI coordinates: $x=-38, y=+6, z=+32$; $Z$-score $=6.4 ; p<0.05$, FWE corrected; with 19 voxels surpassing a threshold of $p<0.001$, uncorrected and masked inclusively with the contrast reading relative to fixation in the patient and control subjects). This effect, at the junction between the precentral sulcus and the inferior frontal sulcus, is projected onto the normalized T1 scan of the patient, which shows the left putamen damage in the coronal (middle) slice. Enhanced activation for the patient was also observed, but not shown, in the left thalamus ( $Z$-score $=5.3$; size $=11$ voxels), which was already a region of interest from our previous DCM analysis. Bottom, The relative effect sizes for reading in the patient (black bar) and the control subjects (gray bars). Differential activation was observed even though in-scanner reading accuracy was matched in the patient and control subjects.

recovery for a given function regardless of lesion size (Miyai et al., 2000; Kawanishi et al., 2002; Fridriksson, 2010; Kim and Jang, 2013).

\section{Results}

\section{In-scanner performance}

In the fMRI experiment, a response was considered correct when all three stimuli in a triad were read/named correctly. Over our healthy control subjects, accuracy across sessions was on average $99 \pm 1 \%$ for word reading and $90 \pm 9 \%$ for object naming. In the patient, accuracy across sessions was $100 \%$ for word reading and $66 \%$ for object naming. In $40 \%$ of the errors made under speeded naming, the patient was able to name two of three objects correctly in those triads.

\section{Part 1: identifying areas that might compensate for loss of the} left putamen

As expected, the patient had no activation in her damaged left putamen compared with the control subjects (i.e., control subjects > patient: $Z=8.6$ for reading-fixation; and $Z=9.0$ for naming-fixation). In contrast, the patient showed enhanced activation (Fig. 4) in part of the left PM (MNI coordinates: $x=$ $-38, y=+6, z=+32)$ during reading relative to fixation $(Z=$ $7.4)$, naming relative to fixation $(Z=4.8)$, reading relative to saying " $1,2,3$ " to unfamiliar symbols $(Z=6.4)$, and naming relative to saying " $1,2,3$ " to unfamiliar nonobjects $(Z=4.3)$. The difference between the patient and control subjects was not significant ( $p<0.05$, uncorrected) in PM during saying " $1,2,3$ " to unfamiliar stimuli. Overactivation in PM designated it as a potentially compensatory region that could be investigated and validated further (Fig. 4). The PM area was thus included in the
DCM analyses to test whether and how it contributed to articulatory activity in the motor cortex.

Part 2: identifying whether and how the compensatory areas contribute to speech production

The DCM model with the highest evidence in the patient included all connections between the input region (vOCC) and all other intact regions (Fig. 2). However, there were no connections to and from the putamen (Table 3 ), as would be expected when data are extracted from a lesioned (dysfunctional) region (Fig. 5). In contrast, the best model for the control group was a fully connected model including all connections to and from the putamen.

Interestingly, the connection strengths for the patient were mostly within the normal range (Fig. 6). Those below the normal range were all those pertaining to the putamen, and the task-dependent modulations on all those feeding into the motor output area (MC; Fig. 6, columns $1-10,13,21$, and 28). Those at the top or above the normal range were all those driving the premotor area (PM; Fig. 6, columns 22-25) and all the endogenous inputs and outputs to the thalamus (Fig. 6, columns 11-22), with the exception of the connection between the thalamus and motor output area (Fig. 6, column 21). The most significant increase in connection strength for the patient relative to control subjects was observed on the connection from the thalamus to the premotor cortex during naming and reading (Crawford-Howell $t$ score $=6.3 ; p<0.05$, Bonferroni correction for multiple comparisons).

These results indicate that the overactivation in PM, reported in Part 1, was the consequence of increased connectivity from other parts of the network [thalamus, vOCC, anterior occipitotemporal cortex], during speech production tasks (naming and reading). The DCM results therefore verify the overactivation as well as indicate the mechanisms that resulted in the overactivation in PM.

Part 3: validating the patient findings by testing whether and how the compensatory pathways are used in neurologically normal control subjects

The aim of this analysis was to dissociate different speech production pathways that did and did not include connectivity through the putamen. A dissociation was defined by a negative relationship, across the control subjects, between the strength of connectivity in two different connections. We focused on finding any connections where the connectivity strength was inversely proportional to that in vOCC $\rightarrow$ PUT. We chose the endogenous connectivity strength (Table 3 ) of the connection vOCC $\rightarrow$ PUT as the independent variable because we had already established in our previous study that the connection from the driving region to PUT plays an important role in reading (Seghier and Price, 2010). None of the negative correlations with vOCC $\rightarrow$ PUT were significant at $p<0.05$ with Bonferroni correction for the number of 
connections investigated. However, as illustrated in Figure 6 (bottom bar graph), there was a consistent trend for all connections involving PM to be negatively correlated with vOCC $\rightarrow$ PUT, with one noticeable significant effect ( $p<0.05$, uncorrected) involving the connection $\mathrm{vOCC} \rightarrow \mathrm{PM}(r=-0.39, p=0.03, \mathrm{df}=$ $23)$. A similar correlation profile was obtained when we looked at the correlations across subjects in terms of effective connectivity during reading and naming. By construction, modulatory parameters are additive (Friston et al., 2003); thus, the effective connectivity when reading and naming are "on" equates to the sum of the baseline parameters in the A-matrix plus the task-dependent modulations in the B-matrix. Again, the most significant negative correlation in effective connectivity during reading and naming was between $\mathrm{vOCC} \rightarrow$ PUT and vOCC $\rightarrow$ PM $(r=$ $-0.48, p=0.008, \mathrm{df}=23)$. This tradeoff between the role of the putamen and premotor cortex in the control subjects is consistent with that seen in the patient.

Part 4: testing the explanatory power of the findings in other patients with left putaminal damage

As predicted on the basis of the fMRI results, standardized reading and naming scores were worse (i.e., lower CAT scores) in Group 1 subjects, who had damage to both the putamen and the premotor cortex, than subjects in the other groups $(p<0.05)$, who had damage to either the putamen or the premotor cortex (for more details, see Table 4).

\section{Discussion}

This study combined four complementary analyses to identify and validate neural pathways that compensate for loss of the left putamen during reading and naming. In Part 1, we show that our patient with a left capsular-putaminal lesion showed abnormally high activation in the left premotor cortex, a region structurally connected to the putamen (Henry et al., 2004; Postuma and Dagher, 2006; Draganski et al., 2008; Ford et al., 2013). This led us to hypothesize that the increased activation in the left premotor cortex might be compensating for loss of function at the site of the lesion. Indeed, both the premotor cortex and putamen have been associated with motor programming and articulatory coding (Indefrey and Levelt, 2004; Price, 2012). For instance, in a sample of 106 patients with diverse profiles of aphasia, damage to a similar region in the premotor cortex was shown to be strongly correlated with phonological naming errors (Schwartz et al., 2012). Alternatively, the precise location of the premotor region, at the junction between the precentral sulcus and the inferior frontal sulcus (i.e., the inferior frontal junction; Fig. 4), may reflect heightened demands on cognitive control mechanisms during both reading and naming tasks (Derrfuss et al., 2005; Sundermann and Pfleiderer, 2012).

Many previous functional imaging studies have also attributed abnormally high activations in patients to plausible compensatory systems (Turkeltaub et al., 2011). Some have patient controls

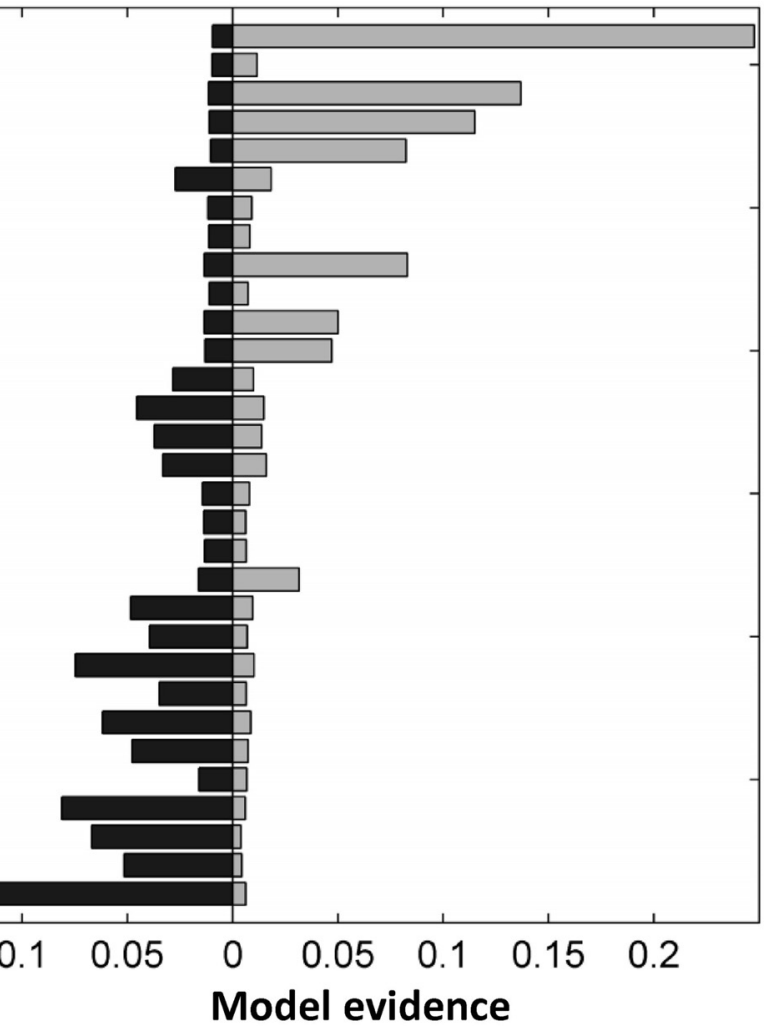

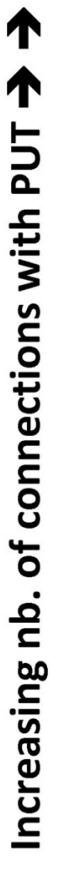
Model evidence

Figure 5. The results of the Bayesian model selection over the 31 models ( $y$-axis) with six regions in the patient (dark bars) and

demonstrated the usefulness and reliability of fMRI for mapping language recovery systems in brain-lesioned patients (Karbe et al., 1998; Mimura et al., 1998; Cao et al., 1999; Calvert et al., 2000; Fernandez et al., 2004; Saur et al., 2006; Ino et al., 2008; Piras and Marangolo, 2009; Wimmer et al., 2010; Turkeltaub et al., 2011; Fridriksson et al., 2012; Szaflarski et al., 2013). Others have attempted to extract useful features from the fMRI responses that can be used for prognostic purposes in stroke patients (Loubinoux et al., 2007; Saur et al., 2010; Wang et al., 2013). However, the explanatory power of these systems for predicting outcome after brain damage has not previously been demonstrated. Our study takes three steps forward by investigating the following: the neural pathways that the compensatory areas are contributing to; validating the dissociation of damaged and compensatory pathways in other populations; and demonstrating the explanatory power of the findings in other patients with new lesion deficit analyses that test whether behavioral outcome after damage to one pathway is better than that after damage to both pathways.

In Part 2, we investigated the neural pathway associated with the left PM that had abnormally high activation in our patient with left putamen damage (as identified in Part 1). Using dynamic causal modeling (Friston et al., 2003), we show that PM was responding to inputs from the other intact regions of our model; and that connectivity increased for naming and reading relative to saying " $1,2,3$." In particular, the strength of the connection from the thalamus to PM was significantly higher in the patient relative to control subjects during the reading and naming tasks. Thus, we contribute to a mechanistic explanation of how a particular recovery pattern emerged through changes in inter-regional interactions using directional functional connec- 


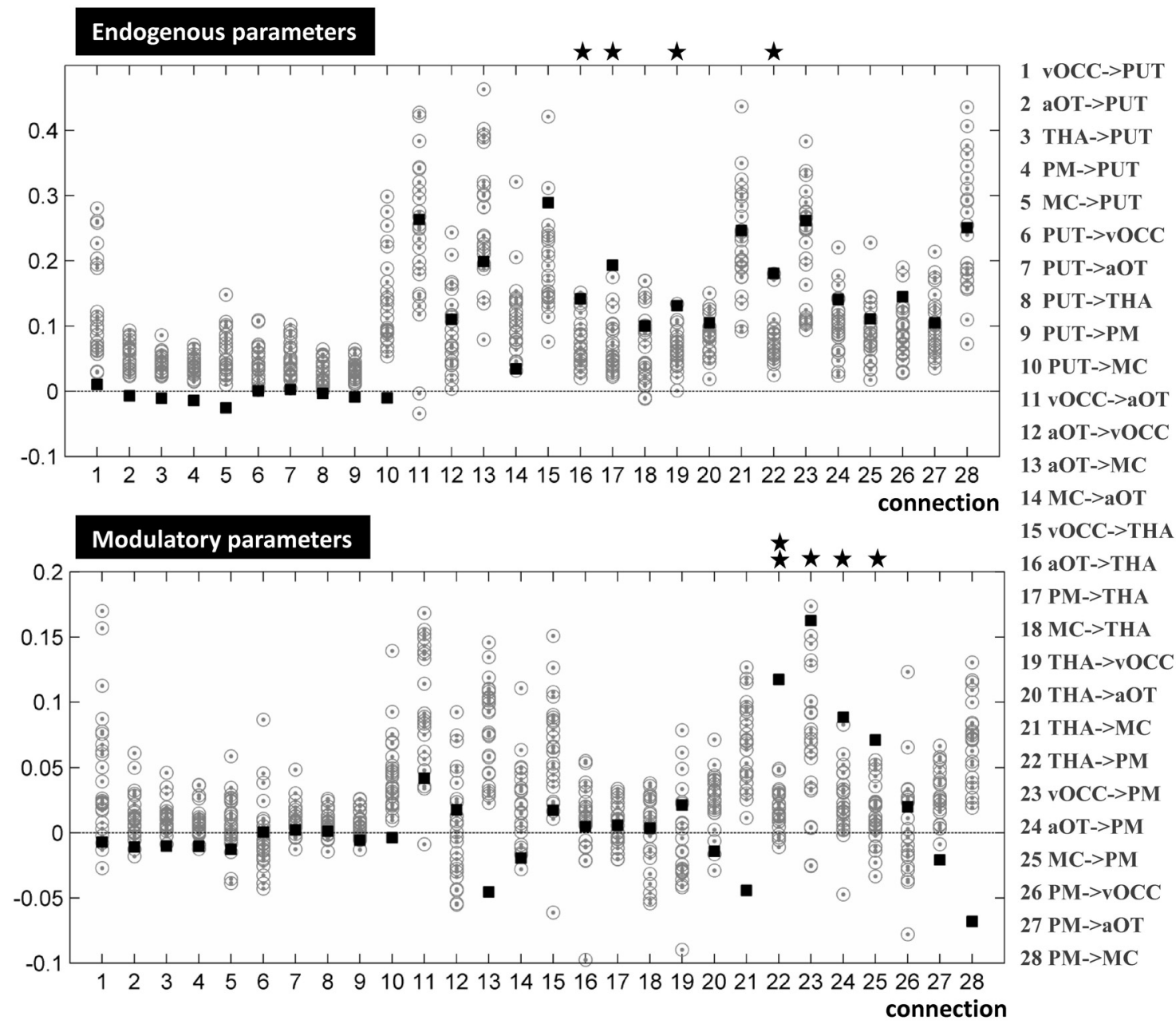

Across-subject correlation: vOCC->PUT

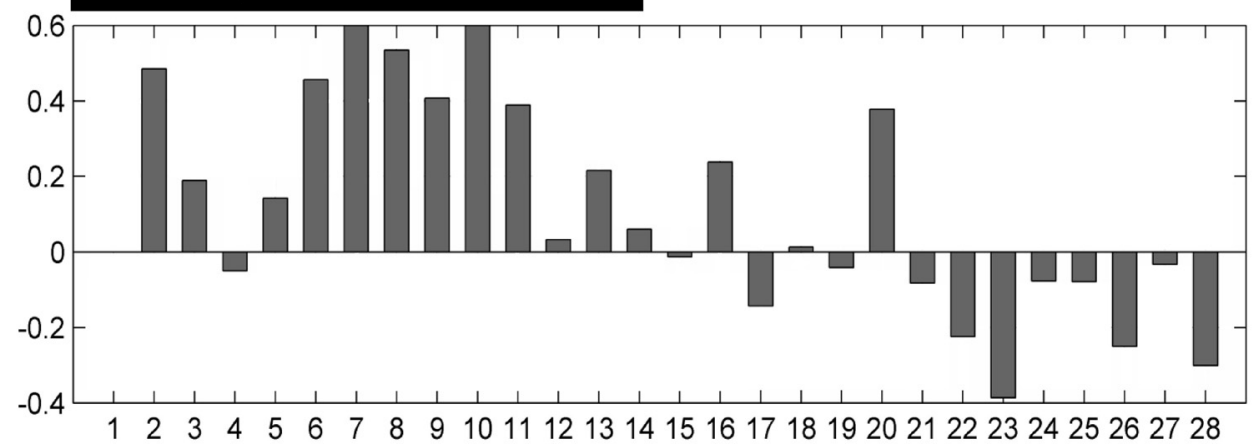

Figure 6. An illustration of the interindividual variability in endogenous connectivity (top) and modulatory parameters for reading and naming (middle) across our 24 healthy subjects. Each circle (gray) illustrates one healthy subject, and the closed squares (black) represent the patient connectivity parameters. Connections with significantly greater effective connectivity parameters in the patient compared with control subjects are indicated by a star $(p<0.05$, uncorrected) or a double star ( $p<0.05$, Bonferroni corrected). The bottom of the figure plots the strength of the across-subject correlations between endogenous connectivity in vOCC $\rightarrow$ PUT and all other connections. Positive values (e.g., in the connections from the putamen) indicate that as connectivity of $\mathrm{vOCC} \rightarrow$ PUT increases, connectivity of the other connection also increases. Negative values (e.g., in the vOCC $\rightarrow$ PM) indicate that as connectivity in v0CC $\rightarrow$ PUT increases, connectivity in vOCC $\rightarrow$ PM is decreasing.

tivity analyses (Seghier et al., 2012). In a previous DCM study, recovery in a patient with damage to the left lentiform nucleus was associated with increased connectivity between language (fusiform and inferior frontal gyri) and control (caudate and anterior cingulate region) systems (Abutalebi et al., 2009). However, only endogenous parameters were assessed in a model that omitted the lesioned region (Abutalebi et al., 2009). Here our multistep approach allowed the remote effects of a focal lesion to be assessed by explicitly incorporating the lesion in the model, and by looking at both endogenous and task-dependent connectivity.

In Part 3, we validated the dissociation of putamen and premotor pathways within the neurologically healthy control population by demonstrating that when connectivity to the left putamen is low, connectivity to the left premotor cortex is high. In other words, there was a tradeoff in the use of one pathway 
over the other, which is the hallmark of functionally dissociated systems (Seghier et al., 2008). The clinical implication here is that, if damage to one pathway can be compensated for via use of another pathway (Seghier et al., 2012), then we can predict that outcome will be poorer when both pathways are lost than when only one pathway is lost (Price and Friston, 2002). More specifically, our fMRI findings predict that, after damage to the left putamen, patients can regain their reading and naming skills by increasing reliance on an alternative neural pathway through the left premotor cortex. Put another way, if the pathway through the left premotor cortex can sustain reading and naming after damage to the left putamen, then patients with damage to both pathways are likely to have worse deficits (and slower recovery) than patients with damage to either the putamen and premotor cortex.

In part 4 , we tested and confirmed these predictions in a new sample of patients with damage to the left putamen $(n=19)$ by showing that those with damage to both the putamen and the premotor cortex had significantly worse speech production than those who had damage to either the putamen or the premotor cortex, even when lesion size was controlled. This strongly supports our conclusion that an intact premotor cortex could facilitate recovery after putaminal damage. However, we cannot rule out that some of the differences in language impairment between Groups 1 and 3A (Fig. 3) might be caused by other uncontrolled alterations in perfusion/metabolism, in particular after subcortical stroke that could affect many cortical regions beyond the focal damage (Vallar et al., 1988; Hillis et al., 2004; Choi et al., 2007). Nevertheless, such uncontrolled alterations in perfusion/metabolism cannot fully explain our findings here because of the nonsignificant differences in language impairment (Table 4) between Groups 2 and 3B, given that all patients in Group 2 had putaminal damage as well. We also acknowledge that there may be many other pathways that might contribute to speech production, and that, ultimately, the most precise predictions will come from understanding all possible ways that the same task can be supported. Nevertheless, we have sufficient evidence here to demonstrate how fMRI can be used to explain and maybe predict differences in language outcome in new patients in whom the compensatory regions were either spared or damaged. With respect to the respective functions of the putamen and premotor pathways, we note that a recent lesion-symptom mapping study associated damage to the left putamen with spontaneous speech at the articulatory level, whereas damage to the left PM impaired speeded naming (Henseler et al., 2014). These results indicate distinct functions that both contribute to the same overall goal—-producing intelligible speech.

We now turn to discuss the implications of our work for understanding the current lesion-deficit mapping literature. Previous lesion studies of patients with subcortical stroke have observed inconsistent effects even in patients with seemingly similar lesion sites (Crosson, 1985; Colombo et al., 1989; D’Esposito and Alexander, 1995), with both fluent and nonfluent aphasia being reported in cases with putaminal lesions (Crosson, 1985; Nadeau and Crosson, 1997). A few studies have nonetheless found that the type and severity of the deficit, and the likelihood of recovery depended on whether damage to the putamen also extended to other neighboring structures, including the globus pallidus (Russmann et al., 2003), the corona radiata (Kawanishi et al., 2002; Komiya et al., 2013), the medial subcallosal fasciculus, and the periventricular white matter (Naeser et al., 1989). Indeed, we note the growing appreciation in the literature that damage to separate brain regions can impair performance on the same language task and the effect of damage to one region will depend on the integrity of other regions (for discussion, see Price et al., 2010). We believe that, by taking into account the multivariate nature of the lesion-deficit associations, for instance by looking at a combination of regions, as in Part 4 of our analyses, many previous discrepancies in lesion-deficit mapping can be resolved, and this may also help to determine reliable and good predictors of language outcome and recovery.

In summary, in a patient with left capsular-putaminal damage, 24 healthy adults and a follow-up with 42 other stroke patients, we have identified and confirmed the importance of a pathway through the left premotor cortex that appears to support reading and naming after damage to the putamen. By showing that a combination of damage to the putamen and the premotor cortex yielded worse performance than in patients who had damage to only one of these regions, our results have direct clinical implications for predicting language recovery after left putaminal damage. They also illustrate how fMRI and connectivity analyses can be used to map recovery pathways, which can then motivate, and be validated by, lesion-deficit analyses. Last but not least, these types of studies may ultimately be useful for interventional studies that target rehabilitation on the identified compensatory regions (e.g., the premotor cortex), for example, using noninvasive brain stimulation techniques to speed up recovery (Naeser et al., 2010; Schlaug et al., 2011).

\section{References}

Abutalebi J, Rosa PA, Tettamanti M, Green DW, Cappa SF (2009) Bilingual aphasia and language control: a follow-up fMRI and intrinsic connectivity study. Brain Lang 109:141-156. CrossRef Medline

Alexander GE, Crutcher MD (1990) Functional architecture of basal ganglia circuits: neural substrates of parallel processing. Trends Neurosci 13:266271. CrossRef Medline

Booth JR, Wood L, Lu D, Houk JC, Bitan T (2007) The role of the basal ganglia and cerebellum in language processing. Brain Res 1133:136-144. CrossRef Medline

Bürgel U, Amunts K, Hoemke L, Mohlberg H, Gilsbach JM, Zilles K (2006) White matter fiber tracts of the human brain: three-dimensional mapping at microscopic resolution, topography and intersubject variability. Neuroimage 29:1092-1105. CrossRef Medline

Calvert GA, Brammer MJ, Morris RG, Williams SC, King N, Matthews PM (2000) Using fMRI to study recovery from acquired dysphasia. Brain Language 71:391-399. CrossRef Medline

Cao Y, Vikingstad EM, George KP, Johnson AF, Welch KM (1999) Cortical language activation in stroke patients recovering from aphasia with functional MRI. Stroke 30:2331-2340. CrossRef Medline

Choi JY, Lee KH, Na DL, Byun HS, Lee SJ, Kim H, Kwon M, Lee KH, Kim BT (2007) Subcortical aphasia after striatocapsular infarction: quantitative analysis of brain perfusion SPECT using statistical parametric mapping and a statistical probabilistic anatomic map. J Nucl Med 48:194-200. Medline

Colombo A, Sorgato P, Scarpa M (1989) Language disturbances following vascular lesions restricted to the left basal ganglia, thalamus, and white matter. Neuropsychology 3:75-80.

Crawford JR, Howell DC (1998) Comparing an individual's test score against norms derived from small samples. Clin Neuropsychologist 12: 482-486. CrossRef

Crosson B (1985) Subcortical functions in language: a working model. Brain Lang 25:257-292. CrossRef Medline

Derrfuss J, Brass M, Neumann J, von Cramon DY (2005) Involvement of the inferior frontal junction in cognitive control: meta-analyses of switching and Stroop studies. Hum Brain Mapp 25:22-34. CrossRef Medline

D’Esposito M, Alexander MP (1995) Subcortical aphasia: distinct profiles following left putaminal hemorrhage. Neurology 45:38-41. CrossRef Medline

Draganski B, Kherif F, Klöppel S, Cook PA, Alexander DC, Parker GJ, Deichmann R, Ashburner J, Frackowiak RS (2008) Evidence for segregated and integrative connectivity patterns in the human basal ganglia. J Neurosci 28:7143-7152. CrossRef Medline

Fernandez B, Cardebat D, Demonet JF, Joseph PA, Mazaux JM, Barat M, 
Allard M (2004) Functional MRI follow-up of language processes in healthy subjects and during recovery in a case of aphasia. Stroke 35:21712176. CrossRef Medline

Ford AA, Triplett W, Sudhyadhom A, Gullett J, McGregor K, Fitzgerald DB, Mareci T, White K, Crosson B (2013) Broca's area and its striatal and thalamic connections: a diffusion-MRI tractography study. Front Neuroanat 7:8. CrossRef Medline

Fridriksson J (2010) Preservation and modulation of specific left hemisphere regions is vital for treated recovery from anomia in stroke. J Neurosci 30:11558-11564. CrossRef Medline

Fridriksson J, Ryalls J, Rorden C, Morgan PS, George MS, Baylis GC (2005) Brain damage and cortical compensation in foreign accent syndrome. Neurocase 11:319-324. CrossRef Medline

Fridriksson J, Richardson JD, Fillmore P, Cai B (2012) Left hemisphere plasticity and aphasia recovery. Neuroimage 60:854-863. CrossRef Medline

Friston KJ, Harrison L, Penny W (2003) Dynamic causal modelling. Neuroimage 19:1273-1302. CrossRef Medline

Gil Robles S, Gatignol P, Capelle L, Mitchell MC, Duffau H (2005) The role of dominant striatum in language: a study using intraoperative electrical stimulations. J Neurol Neurosurg Psychiatry 76:940-946. CrossRef Medline

Henry RG, Berman JI, Nagarajan SS, Mukherjee P, Berger MS (2004) Subcortical pathways serving cortical language sites: initial experience with diffusion tensor imaging fiber tracking combined with intraoperative language mapping. Neuroimage 21:616-622. CrossRef Medline

Henseler I, Regenbrecht F, Obrig H (2014) Lesion correlates of patholinguistic profiles in chronic aphasia: comparisons of syndrome-, modalityand symptom-level assessment. Brain 137:918-930. CrossRef Medline

Hillis AE, Barker PB, Wityk RJ, Aldrich EM, Restrepo L, Breese EL, Work M (2004) Variability in subcortical aphasia is due to variable sites of cortical hypoperfusion. Brain Lang 89:524-530. CrossRef Medline

Houk JC, Bastianen C, Fansler D, Fishbach A, Fraser D, Reber PJ, Roy SA, Simo LS (2007) Action selection and refinement in subcortical loops through basal ganglia and cerebellum. Philos Trans R Soc Lond B Biol Sci 362:1573-1583. CrossRef Medline

Howard D, Swinburn K, Porter G (2010) Putting the CAT out: what the Comprehensive Aphasia Test has to offer. Aphasiology 24:56-74. CrossRef

Hu W, Lee HL, Zhang Q, Liu T, Geng LB, Seghier ML, Shakeshaft C, Twomey T, Green DW, Yang YM, Price CJ (2010) Developmental dyslexia in Chinese and English populations: dissociating the effect of dyslexia from language differences. Brain 133:1694-1706. CrossRef Medline

Indefrey P, Levelt WJ (2004) The spatial and temporal signatures of word production components. Cognition 92:101-144. CrossRef Medline

Ino T, Tokumoto K, Usami K, Kimura T, Hashimoto Y, Fukuyama H (2008) Longitudinal fMRI study of reading in a patient with letter-by-letter reading. Cortex 44:773-781. CrossRef Medline

Josse G, Seghier ML, Kherif F, Price CJ (2008) Explaining function with anatomy: language lateralization and corpus callosum size. J Neurosci 28:14132-14139. CrossRef Medline

Kaji R (2001) Basal ganglia as a sensory gating devise for motor control. J Med Invest 48:142-146. Medline

Karbe H, Thiel A, Weber-Luxenburger G, Herholz K, Kessler J, Heiss WD (1998) Brain plasticity in poststroke aphasia: what the contribution of the right hemisphere? Brain Lang 64:215-230. CrossRef Medline

Kawanishi M, Kajikawa H, Yamamura K, Nomura E, Kajikawa M, Hihara R, Ogawa R, Nagasawa S (2002) Aphasia following left putaminal hemorrhage. Statistical analysis of factors affecting prognosis. Neurol Res 24: 817-821. CrossRef Medline

Kim SH, Jang SH (2013) Prediction of aphasia outcome using diffusion tensor tractography for arcuate fasciculus in stroke. AJNR Am J Neuroradiol 34:785-790. CrossRef Medline

Kim YH, Ko MH, Parrish TB, Kim HG (2002) Reorganization of cortical language areas in patients with aphasia: a functional MRI study. Yonsei Med J 43:441-445. Medline

Komiya K, Sakai Y, Horikoshi T, Naganuma H (2013) Recovery process and prognosis of aphasic patients with left putaminal hemorrhage: relationship between hematoma type and language modalities. J Stroke Cerebrovasc Dis 22:132-142. CrossRef Medline

Loubinoux I, Dechaumont-Palacin S, Castel-Lacanal E, De Boissezon X, Marque P, Pariente J, Albucher JF, Berry I, Chollet F (2007) Prognostic value of FMRI in recovery of hand function in subcortical stroke patients. Cereb Cortex 17:2980-2987. CrossRef Medline

Marchand WR, Lee JN, Thatcher JW, Hsu EW, Rashkin E, Suchy Y, Chelune G, Starr J, Barbera SS (2008) Putamen coactivation during motor task execution. Neuroreport 19:957-960. CrossRef Medline

Mimura M, Kato M, Kato M, Sano Y, Kojima T, Naeser M, Kashima H (1998) Prospective and retrospective studies of recovery in aphasia: changes in cerebral blood flow and language functions. Brain 121:20832094. CrossRef Medline

Miyai I, Suzuki T, Kang J, Volpe BT (2000) Improved functional outcome in patients with hemorrhagic stroke in putamen and thalamus compared with those with stroke restricted to the putamen or thalamus. Stroke 31:1365-1369. CrossRef Medline

Mühlau M, Wohlschläger AM, Gaser C, Valet M, Weindl A, Nunnemann S, Peinemann A, Etgen T, Ilg R (2009) Voxel-based morphometry in individual patients: a pilot study in early Huntington disease. AJNR Am J Neuroradiol 30:539-543. CrossRef Medline

Nadeau SE, Crosson B (1997) Subcortical aphasia. Brain Lang 58:355-402. CrossRef Medline

Naeser MA, Alexander MP, Helm-Estabrooks N, Levine HL, Laughlin SA, Geschwind N (1982) Aphasia with predominantly subcortical lesion sites: description of three capsular/putaminal aphasia syndromes. Arch Neurol 39:2-14. CrossRef Medline

Naeser MA, Palumbo CL, Helm-Estabrooks N, Stiassny-Eder D, Albert ML (1989) Severe non-fluency in aphasia: role of the medial subcallosal fasciculus plus other white matter pathways in recovery of spontaneous language. Brain 112:1-38. CrossRef Medline

Naeser MA, Martin PI, Treglia E, Ho M, Kaplan E, Bashir S, Hamilton R, Coslett HB, Pascual-Leone A (2010) Research with rTMS in the treatment of aphasia. Restor Neurol Neurosci 28:511-529. CrossRef Medline

Oberhuber M, Parker Jones O, Hope TMH, Prejawa S, Seghier ML, Green DW, Price CJ (2013) Functionally distinct contributions of the anterior and posterior putamen during sublexical and lexical reading. Front Hum Neurosci 7:787. CrossRef Medline

Penny WD, Stephan KE, Daunizeau J, Rosa MJ, Friston KJ, Schofield TM, Leff AP (2010) Comparing families of dynamic causal models. PLoS Comput Biol 6:e1000709. CrossRef Medline

Piras F, Marangolo P (2009) Word and number reading in the brain: evidence from a voxel-based lesion-symptom mapping study. Neuropsychologia 47:1944-1953. CrossRef Medline

Postuma RB, Dagher A (2006) Basal ganglia functional connectivity based on a meta-analysis of 126 positron emission tomography and functional magnetic resonance imaging publications. Cereb Cortex 16:1508-1521. CrossRef Medline

Price CJ (2012) A review and synthesis of the first 20years of PET and fMRI studies of heard speech, spoken language and reading. Neuroimage 62: 816-847. CrossRef Medline

Price CJ, Friston KJ (2002) Degeneracy and cognitive anatomy. Trends Cogn Sci 6:416-421. CrossRef Medline

Price CJ, Seghier ML, Leff AP (2010) Predicting language outcome and recovery after stroke: the PLORAS system. Nat Rev Neurol 6:202-210. CrossRef Medline

Rosen HJ, Ojemann JG, Ollinger JM, Petersen SE (2000) Comparison of brain activation during word retrieval done silently and aloud using fMRI. Brain Cogn 42:201-217. CrossRef Medline

Russmann H, Vingerhoets F, Ghika J, Maeder P, Bogousslavsky J (2003) Acute infarction limited to the lenticular nucleus: clinical, etiologic, and topographic features. Arch Neurol 60:351-355. CrossRef Medline

Saur D, Lange R, Baumgaertner A, Schraknepper V, Willmes K, Rijntjes M, Weiller C (2006) Dynamics of language reorganization after stroke. Brain 129:1371-1384. CrossRef Medline

Saur D, Ronneberger O, Kümmerer D, Mader I, Weiller C, Klöppel S (2010) Early functional magnetic resonance imaging activations predict language outcome after stroke. Brain 133:1252-1264. CrossRef Medline

Schlaug G, Marchina S, Wan CY (2011) The use of non-invasive brain stimulation techniques to facilitate recovery from post-stroke aphasia. Neuropsychol Rev 21:288-301. CrossRef Medline

Schwartz MF, Faseyitan O, Kim J, Coslett HB (2012) The dorsal stream contribution to phonological retrieval in object naming. Brain 135:37993814. CrossRef Medline

Seghier ML, Price CJ (2010) Reading aloud boosts connectivity through the putamen. Cereb Cortex 20:570-582. CrossRef Medline 
Seghier ML, Price CJ (2011) Explaining left lateralization for words in the ventral occipitotemporal cortex. J Neurosci 31:14745-14753. CrossRef Medline

Seghier ML, Lee HL, Schofield T, Ellis CL, Price CJ (2008) Inter-subject variability in the use of two different neuronal networks for reading aloud familiar words. Neuroimage 42:1226-1236. CrossRef Medline

Seghier ML, Zeidman P, Neufeld NH, Leff AP, Price CJ (2010) Identifying abnormal connectivity in patients using Dynamic Causal Modelling of fMRI responses. Front Sys Neurosci 4:142. CrossRef Medline

Seghier ML, Neufeld NH, Zeidman P, Leff AP, Mechelli A, Nagendran A, Riddoch JM, Humphreys GW, Price CJ (2012) Reading without the left ventral occipito-temporal cortex. Neuropsychologia 50:3621-3635. CrossRef Medline

Sundermann B, Pfleiderer B (2012) Functional connectivity profile of the human inferior frontal junction: involvement in a cognitive control network. BMC Neurosci 13:119. CrossRef Medline

Swinburn K, Porter G, Howard D (2004) The comprehensive aphasia test. New York: Psychology.

Szaflarski JP, Allendorfer JB, Banks C, Vannest J, Holland SK (2013) Recovered vs. not-recovered from post-stroke aphasia: the contributions from the dominant and non-dominant hemispheres. Restor Neurol Neurosci 31:347-360. CrossRef Medline

Tettamanti M, Moro A, Messa C, Moresco RM, Rizzo G, Carpinelli A, Matarrese M, Fazio F, Perani D (2005) Basal ganglia and language: phonology modulates dopaminergic release. Neuroreport 16:397-401. CrossRef Medline

Turkeltaub PE, Messing S, Norise C, Hamilton RH (2011) Are networks for residual language function and recovery consistent across aphasic patients? Neurology 76:1726-1734. CrossRef Medline

Vallar G, Perani D, Cappa SF, Messa C, Lenzi GL, Fazio F (1988) Recovery from aphasia and neglect after subcortical stroke: neuropsychological and cerebral perfusion study. J Neurol Neurosurg Psychiatry 51:1269-1276. CrossRef Medline

Wang J, Marchina S, Norton AC, Wan CY, Schlaug G (2013) Predicting speech fluency and naming abilities in aphasic patients. Front Hum Neurosci 7:831. CrossRef Medline

Wimmer H, Schurz M, Sturm D, Richlan F, Klackl J, Kronbichler M, Ladurner G (2010) A dual-route perspective on poor reading in a regular orthography: an fMRI study. Cortex 46:1284-1298. CrossRef Medline 